\title{
Salivary Gland-Like Tumor of the Sella
}

\author{
Wouter van Furth, Harley S. Smyth, Eva Horvath, Kalman Kovacs, \\ Fateme Salehi, Michael D. Cusimano
}

Can. J. Neurol. Sci. 2007; 34: 478-482

Tumors arising in the sellar region are predominantly benign, non-invasive pituitary adenomas. Invasive pituitary adenomas (approximately $35 \%$ of the pituitary adenomas) and pituitary carcinomas $(0.1-0.5 \%)$ arise from the same cells in the pituitary gland as the benign tumors, but have different pathology and biological behavior. A wide variety of nonadenomatous lesions involve the sellar region. These include tumors that arise specifically from sellar and suprasellar structures, as well as those that are also found elsewhere in the CNS (e.g. meningioma, glioma, metastasis, etc.). Typical nonadenomatous tumors that originate in the sellar region are craniopharyngioma and Rathke's cleft cyst. The purpose of this paper is to describe another nonadenomatous tumor specific to the sellar region, a salivary gland-like tumor, and review the literature on this subject. This case report will also illustrate the management decisions regarding a patient with multiple medical issues and an aggressive sellar tumor.

\section{Case Report}

\section{History and physical examination}

A 60-year-old male was referred to our hospital for a sellar mass. His previous recent medical history included Billroth II gastric procedure for gastric ulcer, aorto-bifemoral graft for abdominal aortic aneurysm, myocardal infarction, coronary angioplasty, and an asymptomatic descending thoracic aortic aneurysm, which measured $6 \mathrm{~cm}$ in its greatest diameter.

When the patient was initially seen in our hospital he complained of progressive deterioration over months, consisting of anorexia, fatigue and headache, which climaxed in an Addisonian crisis. He was put on full hormonal replacement, with good effect. On physical examination his general appearance was of a man who had undergone accelerated aging. His neurological examination revealed no deficits. At that time repair of his thoracic aneurysm was considered the most urgent medical issue and was planned. Unfortunately, the planned surgery had to be delayed because of a cellulitis in his elbow and later a perforation of his gastric ulcer. In this six week period of waiting for repair of his thoracic aneurysm the patient developed severe headaches that centered around his right eye, proptosis on the right, with diplopia. He developed diabetes insipidus with hypernatremia and became confused. On exam he now had a right partial third nerve palsy, but otherwise no focal deficits. Once the sodium was corrected the patient was cooperative and no longer confused.

\section{Imaging}

The MRI (Figure 1) showed a homogeneously enhancing mass, which appeared to be arising from the pituitary gland and extended into the suprasellar cistern and rostrally either compressed or invaded the optic chiasm. The tumor also extended into the inferior aspect of the anterior third ventricle (stage B, grade II according to Hardy's classification system ${ }^{1}$ ). The optic chiasm was locally thickened. The mass dimensions were $2.5 \times 1.8 \times 2 \mathrm{~cm}$. Both carotid arteries were displaced laterally in the cavernous sinus, but not encased. The thickened chiasm suggested aggressive growth, with infiltration into the infundibulum and chiasm. Compared to previous imaging there was interval growth of $1.5 \mathrm{~cm}$ in diameter in four months. Although the magnetic resonance imaging (MRI) characteristics were consistent with a pituitary macroadenoma, the aggressive growth was more characteristic of a malignant process.

\section{Surgery}

Because of the recent change in neurological status and the interval growth of the sellar tumor on imaging (double in size in four months) it was now believed that the sellar mass was a greater threat to the patient than the aortic aneurysm. Therefore, the patient underwent transsphenoidal resection of his sellar tumor. Residual tumor was left in situ when bleeding of the internal carotid artery, which was easily controlled, complicated the surgery.

\section{Postoperative course}

Post operatively the third nerve palsy improved and the patient did initially well. An angiogram of the internal carotid artery showed normal cerebral perfusion and no sign of carotid injury. Unfortunately, the patient died eight days post-operative from a rupture of his thoracic aortic aneurysm.

From the Department of Neurosurgery (WvF,), University of Amsterdam, Academic Medical Centre, Amsterdam, The Netherlands; Department of Neurosurgery (WvF, HSS, FS, MDC) and Pathology (EH, KK, FS), University of Toronto, Freeman Centre for Endocrine Oncology, St. Michael's Hospital, Toronto, Canada.

ReCeIVEd JANUARY 10, 2007. ACCEPTED IN FinAl FORM June 11, 2007. Reprint requests to: Michael Cusimano, 38 Shuter Street, Toronto, Ontario, M5B 1A6, Canada. 


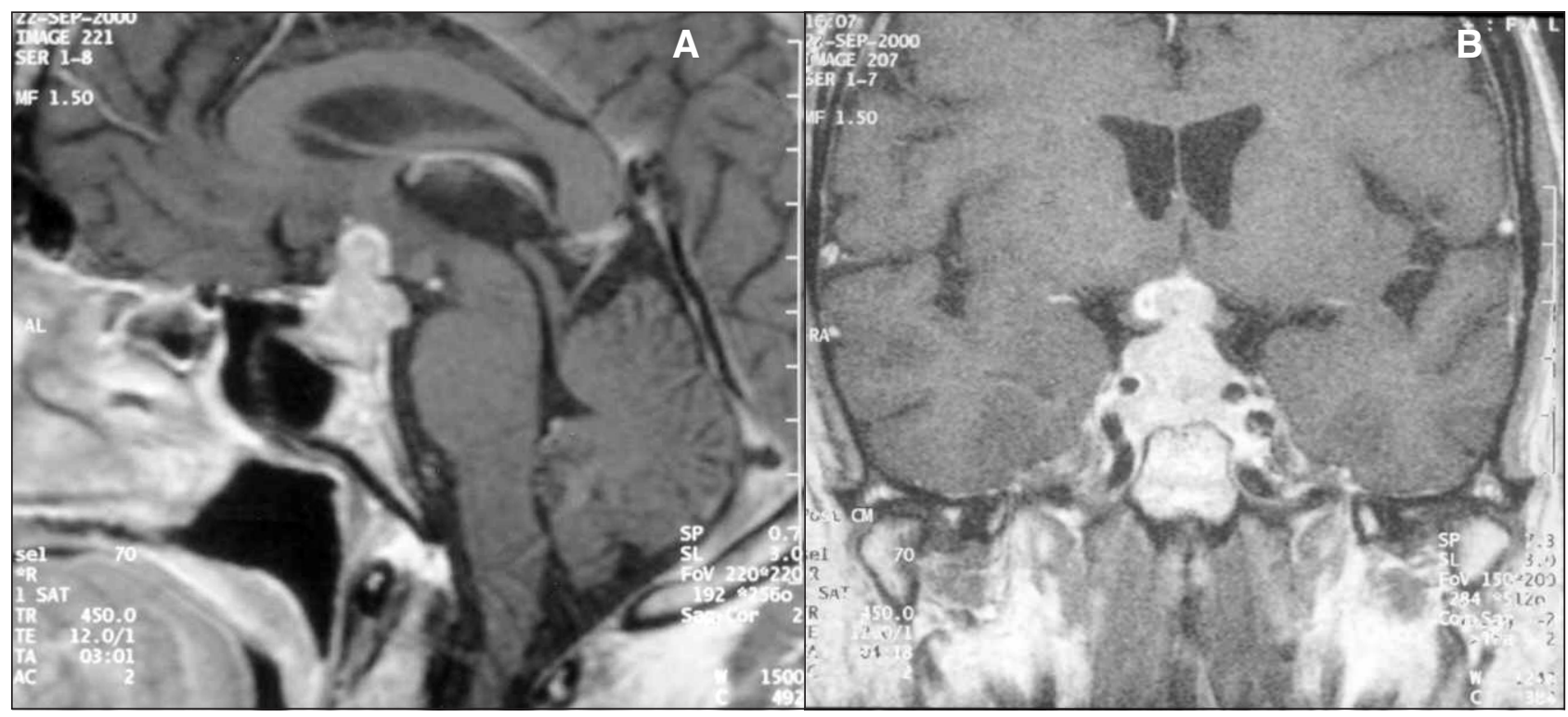

Figure 1: Coronal T1 weighed MRI of the sellar region after intravenous gadolinium administration, showing enhancing sellar mass with suprasellar extension and invasion of the optic chiasm. The internal carotid arteries are laterally displaced in the cavernous sinus.

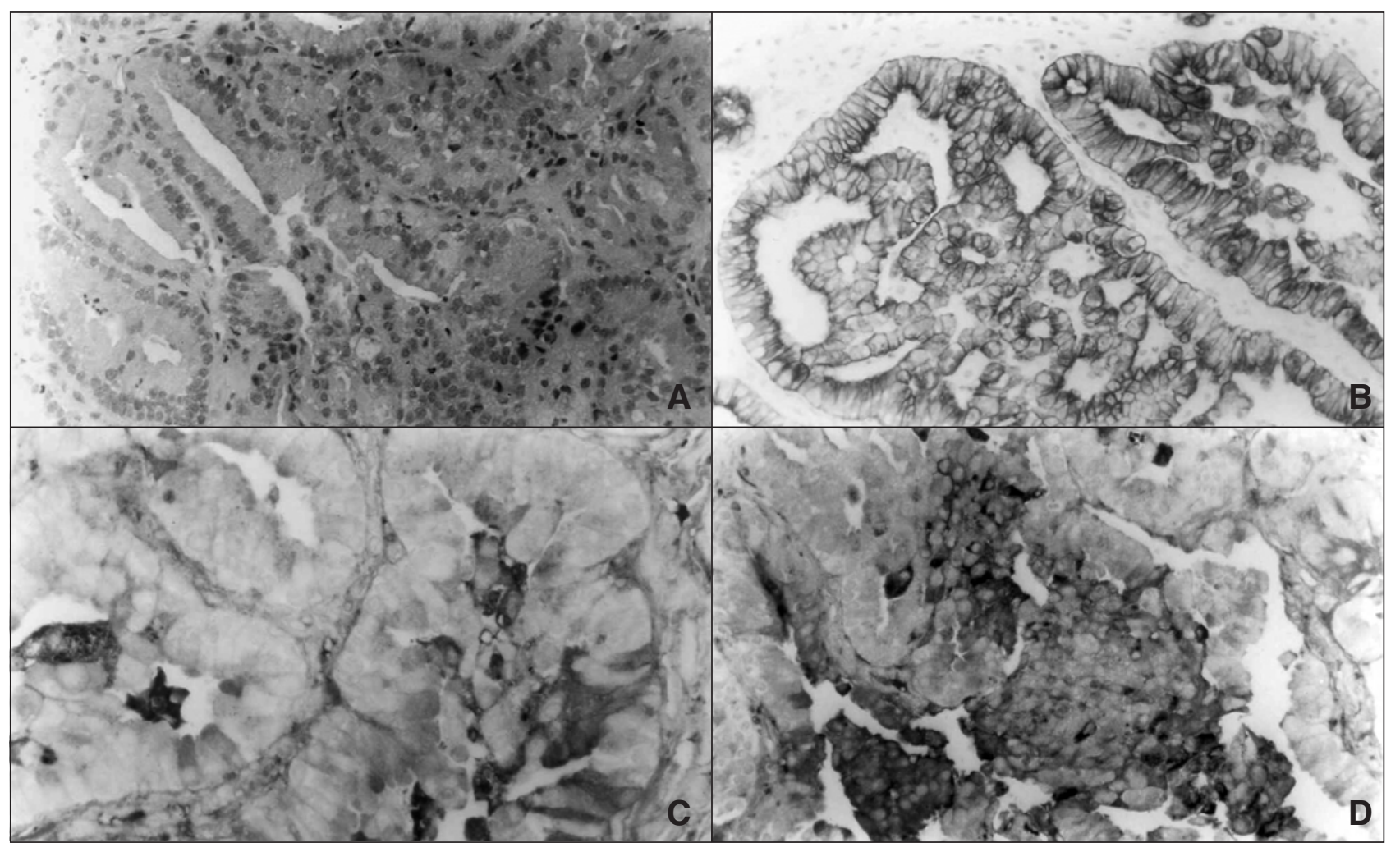

Figure 2: Surgical specimen of sellar mass. A. Well-differentiated neoplasm showing glandular structures (Hematoxylin\&Eosin stain original magnification x25). B. Glandular structures consisting of cytokeratin positive cells (Cytokeratin immunostain original magnification x25). C. Detail of gland formed by cells postive for alpha-1 antitrypsin (alpha-1 antitrypsin immunostain original magnification x40). D. Chymotrypsin postive tumor cells (Chemotrypsin immunostain original magnification x25). 


\section{Autopsy findings}

The complete autopsy showed that the patient had died from a ruptured aortic aneurysm. No other neoplasms were discovered, specifically no primary salivary gland tumor. Residual tumor was present in the sella.

\section{Histological findings}

The surgical specimen showed a well-differentiated neoplasm comprising glandular structures, without nuclear pleomorphism and infrequent mitotic figures (Figure 2A). The ample cytoplasm showed strong PAS positivity at its apical portion. Immunostainings for cytokeratin, alpha-1-antitrypsin and chymotrypsin were positive in the tumor cells (Figures 2B, 2C and 2D). The cells did not stain for mucin. The MIB-1 nuclear labeling was moderate and approximately $3 \%$ of the nuclei were immunopositive. Normal, non-tumorous, adenohypophysis could be identified in junctional areas. The electron microscopy revealed an epithelial neoplasm forming glands. The tumor cells harbored various numbers of granules accumulating within the apical portion of the cells (Figure 3A). Some cells showed perinuclear bundles resembling cytokeratic filaments (Figure 3B). On the basis of morphologic, immunohistochemical and ultrastructural features of the tumor the diagnosis of low grade acinic cell carcinoma was made.

\section{Discussion}

The differential diagnosis of this sellar mass excluded all the different types of pituitary adenomas on the basis of the structural morphology and immunohistochemical staining profile. It is of interest that in the non-tumorous part of the pituitary gland of this patient, cells immunoreactive for $\mathrm{GH}$,
ACTH, and TSH were found in normal levels. PRL positive cells were in the low-normal range and cells immunoreactive for FSH, LH and alpha subunit were unusually scant. The immunoreactivety for digestive enzymes in the neoplastic part of the pituitary gland and the glandular structure on electron miscroscopy clearly indicated the cells of origin of this tumor to be part of the GI-tract. The diagnosis of a salivary gland-like tumor of the sella in our patient was made on the basis of positive immunostaining for cytokeratin, alpha-1-antitrypsin and chymotrypsin, the well differentiated cells with a moderate MIB1 labeling (salivary gland-like tumours of the sella are not rapidly growing), and the glandular structure. Salivary gland tumors are classified as adenoma, carcinoma, non-epithelial tumor or malignant lymphoma. ${ }^{2}$ Common salivary gland tumors are pleomorphic adenoma, mucoepidermoid carcinoma, acinic cell carcinoma and adenoid cystic carcinoma. ${ }^{2,3}$ The histological findings in this patient were consistent with low grade acinic cell carcinoma. Metastatic spread to the sella of a primary tumor in the salivary glands could be excluded at autopsy. The presence of this salivary gland-like tumor in the sella was therefore considered to be a primary nonadenomatous tumor of the sella.

In our patient, as in six previously reported patients, there was no evidence for a salivary gland tumor in major, or minor salivary glands. Therefore, the salivary gland-like tumor of the sella in these six patients was a primary tumor of the sella. So far only nine other patients have been described with salivary glandlike tumors in the sella and two patients had a symptomatic salivary gland rest (see Table 1) ${ }^{4-9}$ One patient had a metastasis from a primary ductal carcinoma of the parotid gland. ${ }^{7}$ Another patient had a primary monomorphic adenoma of the parotid gland with destructive growth of the skull base and invasion in the sella. ${ }^{5} \mathrm{~A}$ third patient with a sellar tumor had an adenoid

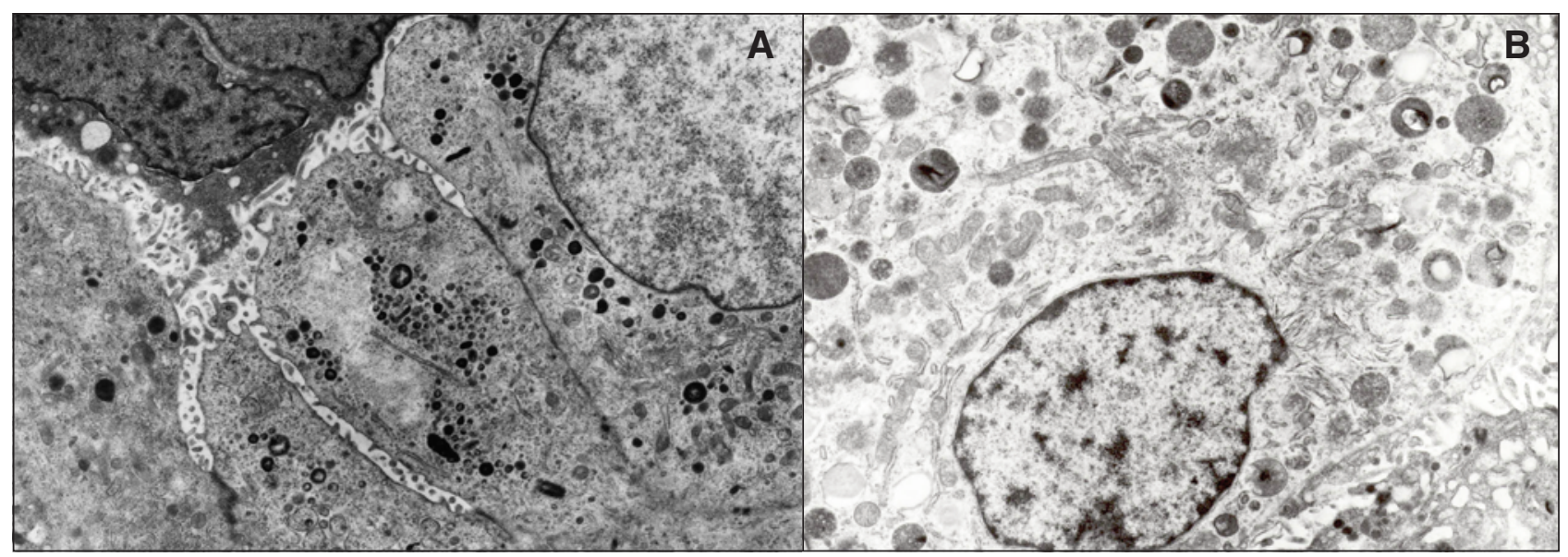

Figure 3: Electronmicroscopic imaging of sellar tumor. A. Part of a gland of the acinic cell carcinoma is shown. The tumor cells are joined by junctional complexes at their apical pole and project numerous short microvilli into the glandular lumen. The characteristic granules usually accumulate within the apical portion of the tumor cells; they vary in size from $250 \mathrm{~nm}$ up to $700 \mathrm{~nm}$, they have variable electron densities and many appear partially extracted. (original magnification x17,200). B. Electronmicrograph depicting the morphologic variations of acinic cell granules. At one pole of the nucleus a small aggregate of cytokeratic filaments is noted (original magnification $x 17,200)$. 


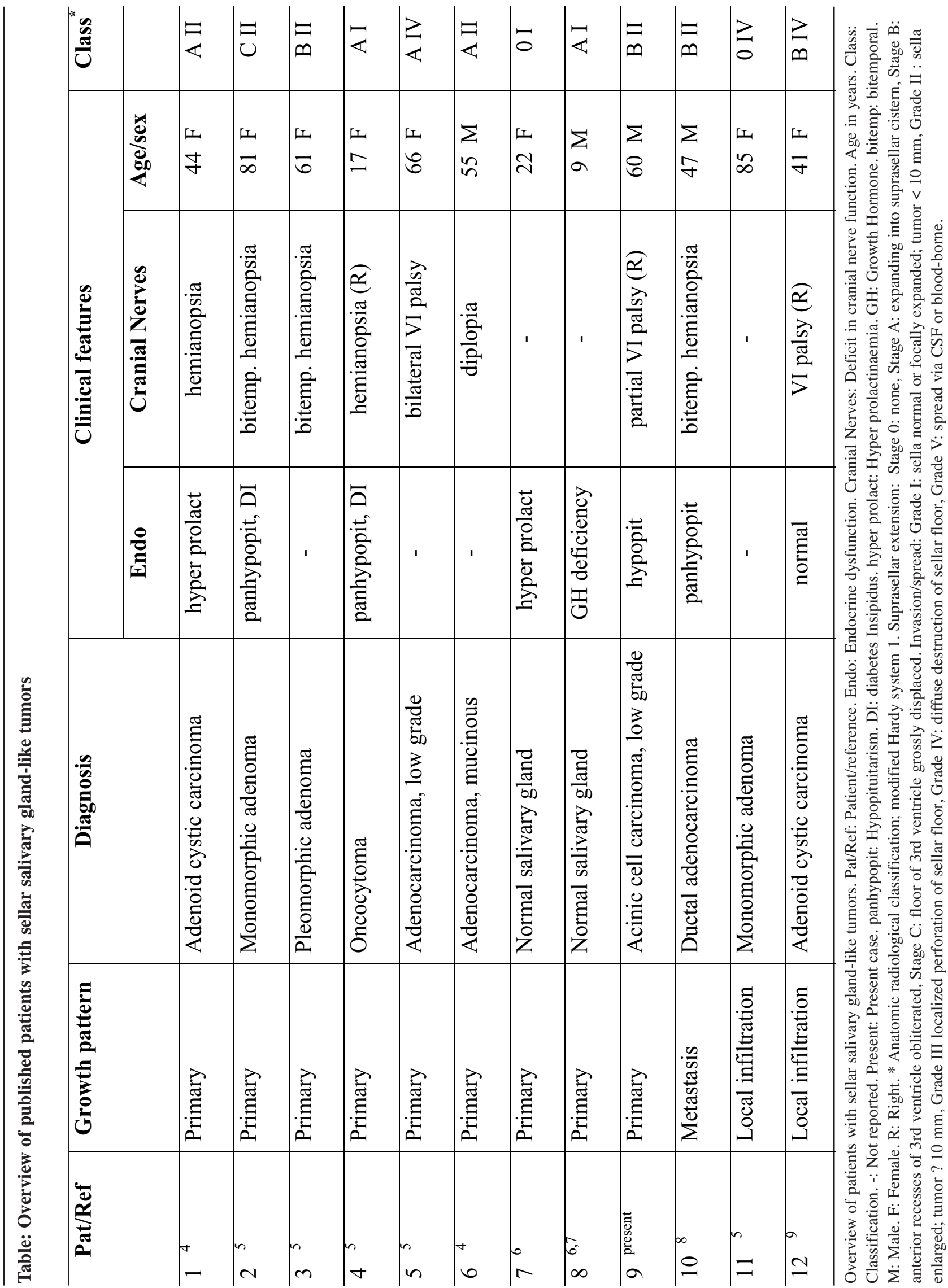


cystic carcinoma in a minor salivary gland in the sphenoid sinus, that locally destructed the skull base and infiltrated the sella. ${ }^{9}$

The clinical features of primary sellar salivary-gland like tumors are summarized in Table 1. There were predominantly female patients, with an average age of 54. All patients had large tumors with supra-sellar extension and cranial nerve involvement. The most common was optic nerve compression (four of six patients). Abducent nerve palsy was also seen relatively frequently. Less than half of the patients had hypopituitarism. On MRI these tumors typically are homogeneously enhancing solid lesions. In a number of patients the cavernous sinus was involved, as was revealed by VI nerve palsy, or demonstrated on MRI. One tumor was described having an irregular shape, with a nodule on top pushing into the brain. Evidence on the MRI for invasion of the optic nerves was described as well.

These primary sellar salivary gland-like tumors are thought to derive from neoplastic transformation of salivary gland rests in the sella. In a series of 2,300 consecutive autopsies, of both adults and children, the pituitary gland was studied; in 78 pituitaries $(3.4 \%)$ salivary gland rests could be demonstrated when standardized three-plane sectioning was used. ${ }^{10}$ In another study salivary gland rests were demonstrated in virtually all pituitary glands, regardless of age, when serial sections were employed. ${ }^{10}$ Interestingly, two patients were described with a symptomatic sellar mass consisting of normal salivary gland, suggesting a particular large sellar salivary gland rest.,

Adenoid cystic carcinoma represents approximately $50 \%$ of all malignant salivary tumors and $35 \%$ of all tumors of the minor salivary glands. These tumors are well known to have a tendency for perineural spread, with tumor going into the parasellar region. ${ }^{11}$ When an adenoid cystic carcinoma originates in the sphenoid sinus it can invade the sella turcica, as was described in one patient. ${ }^{9}$ However, adenoid cystic carcinomas have been described in a number of other intracranial sites, without a known primary tumor. ${ }^{11}$ In these cases the tumor is thought to be derived from heterotopic salivary gland tissue. Only one patient was described with an adenoid cystic carcinoma in the sella, who had no evidence of another primary site. ${ }^{4}$ This adenoid cystic carcinoma was therefore considered a primary tumor of the sella.

The embryological development of the pituitary gland provides an explanation for the occurrence of salivary gland rests in the sella. Embryologically, the anterior lobe of the pituitary gland is derived from Rathke's pouch, an invagination of the primitive oral cavity that extends superiorly toward the base of the brain. ${ }^{12}$ The posterior lobe of the pituitary gland is formed by a downward extension of the floor of the third ventricle. The anterior and posterior lobe fuse and the lumen of Rathke's pouch is partitioned and obliterated during organogenesis. ${ }^{12}$ What remains of Rathke's pouch are a variable number of small colloid filled cysts (Rathke's pouch remnants). In relation to the posterior pituitary, small seromucous glands of the salivary type can often be found communicating with Rathke's cleft remnants. It is not explained how these salivary gland rests get in the pituitary gland. A number of possible explanations have been suggested; direct transfer of intact seromucous glands from the oral cavity, derivation from Rathke's pouch remnants, or induction of pituitary epithelium by salivary gland mesenchyme. 5

\section{REFERENCES}

1. Wilson CB. A decade of pituitary microsurgery. The Herbert Olivecrona lecture. J Neurosurg. 1984;61(5):814-33.

2. Stafford ND, Wilde A. Parotid cancer. Surg Oncol. 1997;6(4): 209-13.

3. Spiro RH, Dubner S: Salivary gland tumors. Curr Opin Oncol. 1990;2(3):589-95.

4. Gilcrease MZ, Delgado R, Albores-Saavedra J. Intrasellar adenoid cystic carcinoma and papillary mucinous adenocarcinoma: two previously undescribed primary neoplasms at this site. Ann Diagn Pathol. 1999;3(3):141-7.

5. Hampton TA, Scheithauer BW, Rojiani AM, Kovacs K, Horvath E, Vogt P. Salivary gland-like tumors of the sellar region. Am J Surg Pathol. 1997;21(4):424-34.

6. Tatter SB, Edgar MA, Klibanski A, Swearingen B. Symptomatic salivary-rest cyst of the sella turcica. Acta Neurochir (Wien). 1995;135(3-4):150-3.

7. Kato T, Aida T, Abe H, Miyamachi K, Hida K, Taneda M, Ogata A. [Ectopic salivary gland within the pituitary gland. Case report]. Neurol Med Chir (Tokyo). 1988;28(9):930-3.

8. McCutcheon IE, Kitagawa RH, Sherman SI, Bruner JM. Adenocarcinoma of the salivary gland metastatic to the pituitary gland: case report. Neurosurgery. 2001;48(5):1161-5.

9. Dickhoff P, Wallace CJ, MacRae ME, Campbell WN. Adenoid cystic carcinoma: an unusual sellar mass. Can Assoc Radiol J. 1993;44(5):393-5.

10. Schochet SS, Jr., McCormick WF, Halmi NS. Salivary gland rests in the human pituitary. Light and electron microscopical study. Arch Pathol. 1974;98(3):193-200.

11. Alleyne CH, Bakay RA, Costigan D, Thomas B, Joseph GJ. Intracranial adenoid cystic carcinoma: case report and review of the literature. Surg Neurol. 1996;45(3):265-71.

12. Bozzola M, Rognone F, Zecca M, Calligaro A. Development of the pituitary and its abnormalities. J Pediatr Endocrinol Metab. 1999;12(Suppl 1):319-27. 